\title{
Further evidence of olfactory ensheathing glia facilitating axonal regeneration after a complete spinal cord transection
}

\author{
Matthias D. Zieglera ${ }^{a}$ Derek Hsua ${ }^{a}$, Aya Takeoka ${ }^{a}$, Hui Zhonga ${ }^{a}$, Almudena Ramón-Cueto ${ }^{d}$, \\ Patricia E. Phelps ${ }^{\mathrm{a}, \mathrm{c}}$, Roland R. Roy ${ }^{\mathrm{a}, \mathrm{c}}$, and V. Reggie Edgerton ${ }^{\mathrm{a}, \mathrm{b}, \mathrm{c},{ }^{*}}$ \\ aDepartment of Integrative Biology and Physiology, University of California, Los Angeles, Los \\ Angeles, CA 90095, USA \\ bDepartment of Neurobiology, University of California, Los Angeles, Los Angeles, CA 90095, USA \\ 'Department of Brain Research Institute, University of California, Los Angeles, Los Angeles, CA \\ 90095, USA \\ dInstitute of Biomedicine, CSIC, Valencia, Spain
}

\begin{abstract}
Spinal Wistar Hannover rats injected with olfactory ensheathing glia (OEG) have been shown to recover some bipedal stepping and climbing abilities. Given the intrinsic ability of the spinal cord to regain stepping with pharmacological agents or epidural stimulation after a complete midthoracic transection, we asked if functional recovery after OEG injections is due to changes in the caudal stump or facilitation of functional regeneration of axons across the transection site. OEG were injected rostral and caudal to the transection site immediately after transection. Robotically assisted step training in the presence of intrathecal injections of a $5-\mathrm{HT}_{2 \mathrm{~A}}$ receptor agonist (quipazine) was used to facilitate recovery of stepping. Bipedal stepping as well as climbing abilities were tested over a 6-month period post-transection to determine any improvement in hindlimb functional due to OEG injections and/or step training. The ability for OEG to facilitate regeneration was analyzed electrophysiologically by transcranially stimulating the brainstem and recording motor evoked potentials (MEP) with chronically implanted intramuscular EMG electrodes in the soleus and tibalis anterior with and without intrathecal injections of noradrenergic, serotonergic, and glycinergic receptor antagonists. Analyses confirmed that along with improved stepping ability and increased use of the hindlimbs during climbing, only OEG rats showed recovery of MEP. In addition the MEP signals were eliminated after a re-transection of the spinal cord rostral to the original transection and were modified in the presence of receptor antagonists. These data indicate that improved hindlimb function after a complete transection was coupled with OEG-facilitated functional regeneration of axons.
\end{abstract}

\section{Introduction}

While the results of studies on the effects of olfactory ensheathing glia (OEG) in repairing an injured spinal cord have been highly variable, so have the experimental paradigms used to determine the reparative potential of these cells, differing in the type and severity of injury, mixture of cell types, duration of transplant, transplantation procedures, and parameters used to define regeneration (Frannsen et al., 2007). One of the more important

(c) 2011 Published by Elsevier Inc.

"Corresponding author at: Department of Physiological Science, University of California, Los Angeles, 621 Charles E. Young Drive, Los Angeles, CA 90095-1527, USA. Fax: +1 310933 1965. vre@ucla.edu (V.R. Edgerton).

Supplementary materials related to this article can be found online at doi:10.1016/j.expneurol.2011.01.007. 
questions yet to be answered conclusively is whether OEG can facilitate regeneration of axons after a complete spinal cord transection. We therefore hypothesized that OEG implanted immediately after a complete spinal cord transection can restore functional connections between the rostral and caudal spinal cord stumps. Previous studies showed improvement in hindlimb function in OEG spinal rats, but it is unclear whether this improvement was attributable to regeneration of axons and/or to reorganization of the neurons in the caudal stump (Ramón-Cueto et al., 2000, Lu et al., 2002; Keyvan-Fouladi et al., 2003; Verdú et al., 2003; García-Alías et al., 2004; Polentes et al., 2004; López-Vales et al., 2007; Kubasak et al., 2008). Some anatomical data are consistent with the presence of regeneration, but these data are not conclusive (Ramón-Cueto et al., 2000; Takeoka et al., 2009,2010 ). In the present study we focused on a battery of functional (behavioral, electrophysiological, and pharmacological) assessments during 6 months post-transection and OEG injections, some of which were performed before and after re-transection of the spinal cord.

We observed motor-evoked potentials (MEP) only in OEG rats. These MEP were modified by step training and their amplitudes could be modulated by yohimbine, a NA receptor antagonist, cyproheptadine, a 5- $\mathrm{HT}_{2}$ receptor antagonist, and/or strychnine, a glycinergic receptor antagonist. In addition, the MEP were eliminated when the spinal cord was retransected rostral to the original transection site.

\section{Methods}

\section{Experimental design}

Spinal cord transection-All procedures were approved by the Chancellor's Animal Research Committee at the University of California, Los Angeles and followed the American Physiological Society Animal Care Guidelines. All surgical procedures were performed under aseptic conditions with the rats deeply anesthetized using isoflurane gas via facemask as needed. The spinal cords of 42 Wistar Hannover rats, 10-12 week old, were transected completely at spinal cord level T8-T9 as previously described (Kubasak et al., 2008). The paravertebral muscles were retracted, a partial laminectomy of the T8 and T9 vertebrae was performed, and the dorsal dura was opened with an ' $\mathrm{H}$ ' cut to expose the spinal cord. The spinal cord then was completely transected with micro-scissors. Two surgeons independently verified a complete transection by passing a glass probe through the site and lifting both cut ends of the spinal cord. The paravertebral muscles and fascia were sutured using 4-0 chromic gut and the skin incisions closed with 4-0 Ethilon suture.

After surgery the rats were placed in an incubator maintained at $37^{\circ} \mathrm{C}$ until fully recovered. The rats were given lactated Ringers ( 5 cc, s.c.) to prevent dehydration. Baytril $(5 \mathrm{mg} / \mathrm{kg}$, s.c., b.i.d., enrofloxacin, Bayer HealthCare LLC), a general antibiotic, and buprenex (0.05 $\mathrm{mg} / \mathrm{kg}$, s.c., b.i.d., buprenorphine hydrochloride, Reckitt Benckiser Healthcare (UK) Limited), an analgesic, were administered during the first two days post-surgery. Manual bladder expressions were performed three times per day for the first two weeks and then twice daily, at $12 \mathrm{~h}$ intervals, thereafter. Rats were housed individually in polycarbonate cages in a room maintained at $26 \pm 1{ }^{\circ} \mathrm{C}$ with $40 \%$ humidity and a $12: 12 \mathrm{~h}$ light:dark cycle. Dry kibble and water were provided ad libitum and pieces of fruit were given daily.

OEG harvesting and injections-OEG were obtained from olfactory bulbs of Wistar Hannover rats, 8-12 weeks old, and were immunopurified with the p75-receptor antibody. Cells were re-suspended at a concentration of 100,000 cells per $\mu 1$ of serum-free Dulbecco's Modified Eagle's Medium. Media with OEG (22 rats) or without OEG (20 rats) were injected into the spinal cord, $1 \mathrm{~mm}$ rostral and caudal to the transection site. Four injections 
of $\sim 50,000$ cells were made into each stump. These procedures were described in RamónCueto et al. (2000) and Muñoz-Quiles et al. (2009).

Animal groups-Forty-two rats were separated into the following groups: Media untrained $(n=10)$, Media trained $(n=10)$, OEG untrained $(n=11)$ and OEG trained $(n=$ 11). Six rats from each of the untrained groups were used to test climbing ability. Responses to brainstem stimulation were recorded from two intact rats implanted with intramuscular EMG electrodes (see below).

Intramuscular EMG implantation procedures-Three months post-transection intramuscular EMG electrodes were implanted in the soleus (an ankle extensor) and tibialis anterior (TA, an ankle flexor) muscles bilaterally. A skin incision was made along the sagittal suture of the skull and the muscles and connective tissues covering the skull were reflected laterally. The skull was thoroughly dried and three stainless steel screws were firmly inserted into the exposed bone. An Omnetics connector was placed between the screws and rigidly affixed to the bone using dental cement. Multistranded, Teflon-coated stainless steel wires (AS632, Cooner Electronics) connected to gold-plated pins in the head connector were passed subcutaneously to the lower legs. Pairs of wires were passed into each muscle belly using a 23 -gauge needle and a small notch $(\sim 0.5-1.0 \mathrm{~mm})$ was made in the Teflon coating to make the electrodes. The electrodes were positioned in the mid-belly of each muscle. Each muscle was stimulated through the head connector to assure proper placement of the electrodes. The electrode wires then were anchored at both ends with 4.0 Ethilon suture. All exposed areas were kept moist with $0.9 \%$ saline washes. After implantation, the muscles, fascia, and skin were sutured in layers.

Intrathecal catheter implantation procedures-During the same surgery as the EMG electrode implantation, all rats were implanted with intrathecal catheters. A length of polyurethane tubing (PE-10) was passed through a plastic head connector that was placed between two screws inserted into the exposed skull. A $4 \mathrm{~cm}$ length of tubing was left at the proximal end to be used for the injections. The distal end of the tubing had a tip made of flexible silastic tubing to avoid damaging the spinal cord and was passed subcutaneously to the back incision. A partial laminectomy was performed at vertebral level T11, and the silastic tip carefully placed in the subarachnoid space and then tunneled to spinal level L2L3. The catheter was secured with suture at its entrance into the vertebral column. The exposed tubing at the proximal end was sealed with a metal plug to prevent contamination. The tubing was flushed with sterile saline 3 times per week with a volume of saline equal to the length of the tubing. Before each flushing or injection of specific agents (see below), the exterior tubing was wiped with $70 \%$ alcohol.

\section{Kinematics training/testing}

Step training and testing-The rats were trained with an assist-as-needed robotic step training system (Fig. 1A), in which their ankles are attached to a robotic arm that provides forces according to a programmed algorithm (Cai et al. 2006; Ziegler et al. 2010). The rats were trained three days a week for $20 \mathrm{~min}$ per day using the assist-as-needed training paradigm in combination with injections of quipazine (see below), a 5- $\mathrm{HT}_{2 \mathrm{a}}$ receptor agonist. Rats from both the trained and untrained groups were tested monthly for their stepping ability while supporting $20 \%$ of their body weight at a treadmill speed of $13.5 \mathrm{~cm} /$ $\mathrm{s}$ without any assistance from the robotic system. Training and testing during the third and fourth months were interrupted by the implantation of the EMG recording electrodes and intrathecal catheters. Due to the time needed to recover from surgery, the rats were tested once during either the third or fourth month of training. The rats were tested for their stepping ability initially without and then with quipazine injections (intraperitoneally or 
intrathecally, see below) during each testing session. Reflective markers were attached to the hindlimbs during testing and the stepping performance was recorded using four high-speed cameras as described by Kubasak et al. (2008). The markers were analyzed using KinemaTracer (Kissei Comtec). Principal Component Analysis (PCA) was used to determine the consistency of the step trajectories as described by Fong et al. (2005).

Grid climbing test-A climbing grid was used to mimic previous tests that reported increased hindlimb activity during climbing in OEG-compared to Media-injected spinal rats (Ramón-Cueto et al., 2000). The grid was made to match the specifications used by RamónCueto et al. (2000). The ability of the rats to climb the grid at $45^{\circ}, 60^{\circ}$, and $90^{\circ}$ inclines was determined (Fig. 1B). Once per week the rats (6 Media untrained and 6 OEG untrained rats) were placed on the grid at each incline to acclimate them to the climbing apparatus. Their ability to climb was tested at 6 months post-transection. During testing the rats were placed at the bottom of the grid at each degree of incline and were left untouched until they reached the top. Chocolate covered Fruit Loops were placed near the top of the grid to entice the rats to climb. EMG activity was recorded during the climbing tests and the hindlimbs were videotaped to assess the extent of their use during climbing. The video was marked for a "pushoff" and the EMG assessed when a hindpaw was placed on a grid crossbar and the ankle joint extended as the paw lifted off the crossbar and then placed on another crossbar (see Supplemental Videos 1 and 2 for example of "pushoffs").

Quipazine administration-Prior to implantation of the intrathecal tube, quipazine was injected $\sim 15 \mathrm{~min}$ before training intraperitoneally at a dosage of $0.5 \mathrm{mg} / \mathrm{kg}$ (Fong et al., 2005; Ziegler et al., 2010). After the intrathecal tube was implanted the quipazine was administered intrathecally at a dosage of $0.05 \mathrm{mg} / \mathrm{kg} \sim 5 \mathrm{~min}$ before testing (de Leon and Acosta, 2006). A volume of $\sim 20 \mu \mathrm{L}$ of quipazine solution (diluted in sterile water at $1 \mathrm{mg} /$ $\mathrm{mL}$ ) was injected into the intrathecal tube followed by injection of $20 \mu \mathrm{L}$ of sterile saline. Because it is known that $5-\mathrm{HT}_{1 \mathrm{a}}$ and $5-\mathrm{HT}_{7}$ receptors are also important for stepping, kinematics testing was examined using a combination of 8-hydroxy-2-(di-n-propylamino) tertaline (8-OH-DPAT), a 5-HT $1 \mathrm{a}, 7$ agonist, at a concentration of $0.03 \mathrm{mg} / \mathrm{kg}$ and quipazine at a dosage of $0.03 \mathrm{mg} / \mathrm{kg}$ injected intrathecally. We were able to successfully record stepping from 7 rats with this combination: however, 3 of the 7 rats died within two days of the intrathecal injections and therefore we did not continue with this drug combination.

PCA analyses-Improvements in stepping consistency were characterized by measuring the consistency of the repetition of a nominal trajectory. Step trajectories were separated into horizontal and vertical components. Each step was normalized to the same number of data points and the principal components were computed. The first principal component was used as the "nominal" trajectory from the data set. The resulting PCA corresponded to the consistency of stepping with higher PCA percentages reflecting more consistent and therefore better stepping. The rat had to take at least 3 steps during testing to calculate the PCA percentage. A score of $45 \%$ was assigned to any rat that took less than 3 steps (Cai et al., 2006).

Normalized EMG data-MEP responses were normalized to the mean maximum EMG burst amplitude for each muscle during stepping with quipazine. The mean maximum amplitude of a minimum of 30 bursts for each muscle was determined. We then compared the normalized amplitudes between rats. The normalized MEP was obtained using the following equation: $(($ MEP Amplitude $(\mathrm{mV}) / \mathrm{Max}$ EMG during stepping $(\mathrm{mV}) \times 100)$ the result then was multiplied by 100 to obtain the normalized percentage of the maximum amplitude during stepping. 


\section{Electrophysiological determinations}

Pre-transection recordings-Recordings from two intact rats with EMG implants were used for a MEP baseline reading. The rat was anesthetized lightly with $0.7 \%-2 \%$ isoflurane and placed in a hammock to support its body while allowing its legs and arms to be unrestrained. Two stimulating electrodes were placed subcutaneously over the brainstem. The rats were stimulated using a single stimulus of $100 \mu \mathrm{s}$ at a range of $75 \mathrm{~mA}$ to $200 \mathrm{~mA}$ increased incrementally by $25 \mathrm{~mA}$, equivalent to $2.5 \mathrm{mC}$ per stimulus. The rats were given at least 25 stimulations per session with at least $30 \mathrm{~s}$ of rest between stimulations. A constant current stimulator (model DS7AH; Hertfordshire, England) was used to produce the stimulations.

Post-transection recordings-Approximately one month after the transection surgery the rats were tested electrophysiologically confirming a complete transection. For the first month post-transection muscle activity was recorded using acutely implanted bilateral subcutaneous electrodes placed over the medial gastrocnemius and TA muscles as previously reported (Takeoka et al., 2008). To enhance the accuracy of the recordings chronically implanted EMG electrodes were used thereafter (see below). Two rats showed a MEP in all 4 muscles with brainstem stimulation during the 1 month post-transection test and were eliminated from the study.

At four and six months post-transection, i.e., after the chronic intramuscular EMG electrodes were implanted, the rats were tested again for the presence of MEP. After the six-month test the rats were injected intrathecally with each of the following: cyproheptadine (a 5- $\mathrm{HT}_{2}$ receptor antagonist), yohimbine (a $\mathrm{NA}_{2}$ receptor antagonist), and strychnine (a glycine receptor antagonist). Each injection was separated by a minimum of $24 \mathrm{~h}$ and tested on 7 OEG and 8 Media rats, with the exception of cyproheptadine where 5 OEG and 8 Media rats were tested. Modulation of the MEP by these agents was analyzed to determine the role of specific neurotransmitters in the recovery of MEP in OEG rats. Eight OEG and 5 Media rats were re-transected $0.5 \mathrm{~cm}$ rostral to the original transection site and retested for the presence of MEP immediately afterward.

Criteria for MEP_After each brainstem stimulation EMG recordings from the soleus and TA were recorded for $1 \mathrm{~s}$ to identify any MEP responses. A response was considered to be a MEP if it occurred less than $50 \mathrm{~ms}$ after the stimulation and was two standard deviations above the signal noise. The window of $50 \mathrm{~ms}$ was used to allow for delays in signaling that may occur after regeneration of neurons. The delay in the response of a regenerated neuron was unknown. Therefore a window large enough to record any possible signal that was recovered, including the possibility of a multi-synaptic signal and signals from unmyelinated fibers, was used. If more than one peak occurred, the largest amplitude was used to measure latency.

\section{Statistical analyses}

Kinematics and EMG data are reported as mean \pm SEM. One-way ANOVA was used to determine overall differences in training status, EMG, MEP, and response to pharmacological interventions. Two-way ANOVA was used to determine overall differences between Media and OEG trained and untrained groups followed by Tukey posthoc tests to make comparisons among groups. Pearson's correlation was used to determine the linear relationship between selected variables. A $p$ value less than 0.05 was used to define statistical significance. 


\section{Results}

\section{Step training and pharmacologically induced improvements in stepping ability in Media rats}

Stick diagrams and trajectories for a single step of a rat representing the untrained and trained Media groups with and without injections of 5-HT receptor agonists are shown in Figs. 2A and B, respectively. The EMG activity of the soleus and TA muscles corresponding to these rats for single and a mean of 10 steps are shown in Figs. 2C and D, respectively. These data show that the reciprocal activity between the TA and soleus was clearer in the trained than untrained groups and clearest in the group receiving all three interventions. Spinal rats with no interventions had a mean of 0.4 plantar placements $( \pm 0.4$ SEM) during the 20-s test (Fig. 2E). There was a progressive and significant increase in the mean number of plantar placements made with the addition of each intervention, i.e., $25.5 \pm 2.1,32.6 \pm$ 4.9 , and $47.2 \pm 3.6$ plantar placements with quipazine alone, quipazine plus step training, and quipazine plus step training plus 8-OH-DPAT, respectively.

The PCA analyses showed a similar trend (Fig. 2F), i.e., rats receiving no interventions did not generate enough steps to be analyzed and received the lowest possible score of $45 \%$, whereas rats receiving quipazine alone, quipazine plus step training, and quipazine plus step training plus 8-OH-DPAT had scores of $71.9 \pm 2.9 \%, 77.7 \pm 2.2 \%$, and $85.9 \pm 2.8 \%$, respectively. Mean step height was higher in rats treated with quipazine alone $(26.9 \pm 2.3$ $\mathrm{mm}$ ) or with all three interventions $(30.5 \pm 2.7 \mathrm{~mm})$ than when step trained and treated with quipazine $(19.2 \pm 1.8 \mathrm{~mm}$ ) (Fig. $2 \mathrm{G}$ ). Mean step length was longer in the rats treated with all three interventions $(37.5 \pm 3.4 \mathrm{~mm})$ than when treated with quipazine alone $(26.7 \pm 2.4 \mathrm{~mm})$. The mean percent of co-activation between the soleus and TA muscles was higher in rats receiving quipazine alone $(25.1 \pm 3.4 \%)$ than in either group of step trained rats $(11.8 \pm 3.4$ and $9.7 \pm 2.4 \%$ co-activation for the quipazine plus step training and quipazine plus step training plus 8-OH-DPAT groups, respectively) (Fig. 2H). The fact that there is coactivation when the EMG is averaged over multiple steps (Fig. 2D) shows that there is inconsistent timing of muscle bursting between steps.

\section{Stepping ability is greater in OEG than Media rats}

Media and OEG rats were tested monthly for their ability to step on a treadmill at a speed of $13.5 \mathrm{~cm} / \mathrm{s}$ while supporting $20 \%$ of their body weight. A stick diagram of a typical step and the EMG response of the soleus and TA from a representative rat in the Media untrained, OEG untrained, and OEG trained groups at the 4-month time point are shown in Figs. 3A, B and D. For the Media trained group which did not step after EMG electrode implantation, however, an example of a stick diagram of a typical step from the second month with no EMG (prior to the EMG implants) is shown in Fig. 3C. The mean number of plantar placements Fig. 3E) generated during each 20-s session throughout the 6-month period and the step consistency as reflected by the PCA percentage averaged over all testing sessions (Fig. 3F) were higher for the OEG trained than for either group of Media rats. Mean step height was higher and step length longer in Media trained rats than in the Media untrained group and higher in OEG trained than OEG untrained groups (Fig. 3G). For the OEG or Media rats there was no training effect on the number of rats that stepped (data not shown) or on the mean number of plantar placements (Fig. 3E). Therefore, the untrained and trained groups were combined for the OEG and for the Media rats when comparing results over the entire course of the experiment. The number of rats that performed plantar placements was somewhat higher in the OEG than Media groups at all time points except 6 months posttransection, although there was a statistical difference only at the second month time point (Fig. 3H). There were more plantar placements generated in OEG than Media rats at 2 and 3/4 months post-transection (Fig. 3I). The level of co-activation between the soleus and TA 
was similar among the three groups that stepped successfully on the treadmill after the EMG electrodes were implanted (Fig. 3J).

\section{Stepping ability improved after quipazine treatment with training and/or OEG transplantation}

In the presence of quipazine, the consistency of the $x-y$ trajectory during stepping (PCA) and the number of plantar placements was improved by training in both the Media and OEG groups compared to the Media untrained group (Figs. 4A and B). The OEG untrained rats, however, were not different from any other group.

\section{Increased hindlimb usage during climbing after OEG transplantation}

All rats were able to climb at a $45^{\circ}, 60^{\circ}$, and $90^{\circ}$ inclines 6 months post-transection. Although the level of success was similar among groups, the number of times the hindlimbs of each rat were used to push off the apparatus was higher in the OEG than Media groups at all inclines, except $90^{\circ}$ (Fig. 5A). Overall during the climbing test the OEG and Media rats used their hindlimbs an average of 19.8 and 2.5 times, respectively. During climbing the mean EMG burst amplitudes of both the soleus and TA muscles were higher in the OEG than Media rats (Fig. 5B). In addition, the mean EMG amplitude of the soleus was higher in OEG rats when the leg was pushing off the crossbars of the climbing apparatus versus the spontaneous bursting at all other times during climbing.

\section{Time course of recovery of MEP after a complete spinal cord transection}

The MEP response to subcutaneous brainstem stimulation was determined in two intact rats implanted with EMG recording electrodes (Fig. 6A and Table 1). After the spinal cord transection rats were tested with bilateral transcranial stimulation over the brainstem 1 month post-transection to confirm a complete transection of the spinal cord. Two rats showed a response and were eliminated from the study. All other spinal rats showed no response to the stimulation (Fig. 6B). During all subsequent tests there was no recovery of a signal in the Media rats (Fig. 6E and Table 1). At 4 months post-transection we recorded from chronically implanted intramuscular EMG electrodes and 7/20 OEG rats had a MEP in one or both of the TA and soleus muscles (Table 1). Of the 7 rats that had a MEP response, one was an untrained and 6 were trained OEG rats. At 6 months post-transection 13/18 OEG rats had a MEP (Figs. 6C-E; Table 1). All muscles that that had a MEP response at 4 months also had a response at 6 months. Of the 13 rats that had a MEP response at 6 months post-transection, 4 were untrained and 9 were trained OEG rats. The mean amplitude was lower and the mean latency longer for the MEP in both trained and untrained OEG compared to intact rats in both muscles and at both time points. At 6 months posttransection, the mean MEP amplitude was higher and the mean latency shorter in both the TA and soleus of the trained than untrained rats (Table 1). Furthermore, the mean MEP amplitude of the TA was higher than in the intact and untrained rats at the 6-month time point. When the spinal cord of 7 of the 13 OEG rats showing a MEP at 6 months were tested immediately after re-transection, no MEP was observed (Fig. 6F).

To determine if there were any functional benefits associated with the recovery of MEP in the OEG rats, we plotted the normalized amplitude of the MEP in each muscle of OEG untrained rats against climbing ability (Figs. 7A and B) and OEG trained and untrained rats against stepping ability (Figs. 7C and D). There was a significant positive correlation between climbing ability and the MEP amplitude in the soleus $(r=0.65)$, but not the TA $(r=$ 0.53 ). No relationship was observed between stepping ability and MEP amplitude in either muscle (Figs. 7C and D). When training status was considered, the MEP amplitude was higher (Fig. 7E) and the latency shorter (Fig. 7F) in the OEG trained than OEG untrained 
rats. Training status had no effect on the incidence of the MEP response to brainstem stimulation (Fig. 7G).

\section{Effects of receptor modulation on MEP}

Compared to pre-drug administration, OEG rats showed a consistent and similar decrease in MEP amplitude and response incidence in both the soleus and TA muscles after injection of yohimbine (Fig. 8A). In addition, the MEP responses were similar in the trained and untrained groups (Fig. 8B). In contrast, the MEP did not significantly change in any muscles between pre- and post-drug administration when the same OEG rats were injected with either cyproheptadine (Fig. 9A) or strychnine (Fig. 10A), except for a longer latency in the TA after strychnine injection. When training status was considered, MEP amplitude in OEG untrained rats was higher post-than pre-drug injection for both cyproheptadine (Fig. 9B) and strychnine (Fig. 10B), whereas MEP amplitude was lower in trained OEG rats post- than pre-cyproheptadine injection. Mean MEP latency in trained OEG rats was shorter post- than pre-cyproheptadine injection (Fig. 9B), and longer in both groups after injection of strychnine (Fig. 9B). In addition there was a significant difference in the MEP amplitude between the trained and untrained groups after strychnine injection (Fig. 10B). When these changes were plotted against stepping and climbing performance, no significant correlations were found (data not shown).

\section{Discussion}

In the present study we show that in addition to improved hindlimb function, injection of OEG facilitated regeneration of axons across a complete mid-thoracic spinal cord transection. More specifically as in previous studies, we observed that OEG spinal rats had a better climbing performance than Media rats 6 months after injection of OEG (RamónCueto et al. 2000; Muñoz-Quiles et al., 2009). TA and soleus EMG activity in OEG rats was higher than in Media rats, particularly in the soleus when the hindlimb pushed off the grid while climbing. Furthermore, the normalized MEP amplitude in the soleus correlated directly with hindlimb usage during climbing. We also observed improved plantar placement during stepping in OEG rats similar to Takeoka et al. (2008), although the stepping ability was not correlated with the MEP responses. Stepping performance peaked between the second and fourth months post-transection, whereas the incidence of electrophysiological responses increased throughout the six months of testing.

We observed MEP post-transection only in OEG rats, a finding consistent with Takeoka et al. (2008). The MEP had significantly lower amplitudes and longer latencies compared to recordings in intact rats, also consistent with MEP recordings using subcutaneous acute electrodes reported by Takeoka et al. (2008). These findings suggest that although multisynaptic pathways had developed, the degree of re-connectivity of the descending neuronal pathways was small relative to these pathways in intact rats. To verify that these signals were the result of re-connectivity across the lesion site, the spinal cord was re-transected rostral to the original transection site. This eliminated all MEP in each of the OEG rats tested whereas there were no changes detected in the Media rats.

Intrathecal injections of selected pharmacological antagonists allowed us to assess whether there were NA, 5-HT, or glycinergic components to the supraspinal-muscle connections that were re-established. In all spinal rats that showed a MEP there was a lower amplitude and incidence of the signal after injection of yohimbine, a NA receptor antagonist. Previous studies reported that intrathecal injections of yohimbine can decrease the stepping ability of intact rats or rats having an incomplete spinal injury, but no effect on stepping after a complete transection was reported even though NA receptors were present (Giroux et al., 2001). The decreased response in amplitude and incidence of MEP is consistent with there 
being a NA receptor excitatory component to at least some of the re-established connections. This modulation could have occurred over a single or multiple points along the brainstemmuscle pathways. Given the wide distribution of the pharmacological effects on many different types of cells (Hochman et al., 2001) it seems likely that some of this modulation occurred pre-synaptically to the motoneurons as opposed to only a modulation of the electrophysiological membrane properties of the motoneurons.

Step training significantly improved stepping in OEG rats, and the OEG trained rats also had higher normalized MEP amplitudes than OEG untrained rats. While stepping improved in all rats (Media and $\mathrm{OEG}$ ) after intrathecal injections of quipazine, a 5- $\mathrm{HT}_{2 \mathrm{~A}}$ receptor agonist, the stepping was further enhanced by assist-as-needed robotic training and even more so by injections of a 5-HT $1 \mathrm{~A}, 7$ receptor agonist, 8-OH-DPAT. We observed previously that robotic step training in combination with quipazine up-regulates $5-\mathrm{HT}_{2 \mathrm{~A}}$ receptors in spinal mice (Otoshi, 2008) and this may have contributed to the greater improvement of OEG trained rats in the presence of quipazine.

Further evidence of a 5-HT component of the training effect in OEG rats is suggested by the 5-HT blocking experiments. For example, there were training dependent effects of cyproheptadine on the MEP amplitude and latency, with both measures being lower in the trained than untrained OEG rats after blocking with cyproheptadine. This is consistent with the reported up-regulation of $5-\mathrm{HT}_{2 \mathrm{~A}}$ receptors after robotically assisted training in the presence of quipazine (Otoshi, 2008).

Strychnine, a glycinergic antagonist, increased the amplitude of the MEP of the untrained rats. These results are consistent with the reported marked improvement in stepping of complete spinal cats that had little or no stepping ability, while strychnine had little effect on trained cats and rats that could already step (de Leon et al, 1999; unpublished observations). These contrasting results probably reflect the up-regulation of glycinergic receptors that occurs after a complete spinal lesion, an elevation of the chloride equilibrium potential (Boulenguez et al., 2010; Edgerton and Roy, 2010), and/or the fact that this up-regulation returns toward normal levels with step training.

The pharmacological experiments reflected in the multiple parameters measured and the multiple mechanisms through which the pharmacological antagonists could have affected the total circuitry are complex. The general conclusion is that there were functional reconnections, i.e., synapses capable of generating electrical potentials, formed only in OEG rats. Based on the relatively long latencies observed, most, if not all of these brain-to-muscle connections were most likely multi-synaptic. With one exception, i.e., the latency after the injection of strychnine, this re-connectivity was similar in circuits projecting to a flexor and an extensor motor pool. Finally there was evidence that step training influenced the formation of these re-connections having a 5- $\mathrm{HT}_{2}$ or glycinergic, but not a $\mathrm{NA}_{2}$, component. But the over-riding conclusion of most importance is that among these newly formed connections, there were multiple observations strongly suggesting that there were neurotransmitter components involving $\mathrm{NA}_{2}, 5-\mathrm{HT}_{2}$, and glycinergic receptors among the new supraspinal-muscle connections made and that this occurred exclusively in OEG rats. The effects of each receptor antagonist on the MEP amplitude, reflecting the strength of the signal (relative number of excitatory vs. inhibitory synapses activated), after each experiment are shown in Fig. 11. Although only MEP amplitudes are illustrated in Fig. 11 significant differences also were observed in the latency, reflecting the predominant number of synapses placed "in series", and the incidence of MEP, reflecting the robustness (consistency) of the signal (Figs. 8-11). 
We have shown evidence of functional axonal connections across a complete spinal cord transection in OEG spinal rats. The effects of these regenerated axons on the recovery of stepping ability, however, appear to be inconsistent, i.e., the stepping performance was enhanced in some rats but either not affected or suppressed in others. In fact, there was no correlation between the recovery of MEP and the number of steps performed during the monthly testing. In contrast there was a strong correlation between the MEP amplitude and hindlimb activity during climbing. The improved hindlimb function during climbing versus the limited and inconsistent improvement in stepping in rats demonstrating MEP may be related to the nature of the tasks. Perhaps climbing requires more involvement of supraspinal control compared to the more automatic movements for stepping. The influence of regenerated axons on bipedal stepping was not significant and, in fact, seems to have caused variable responses in different rats. Some rats had improved stepping while others showed no change. In effect, it appears that there were behavioral effects of OEG and training on the lumbosacral locomotor circuitry as well as in facilitating regeneration and influencing the newly re-established supraspinal-spinal reorganization that seems to occur once new connections are made.

The present data show that the OEG facilitated axon regeneration involves one or more neurotransmitter systems. Furthermore, step training appears to increase the magnitude of the MEP in the presence of OEG. Overall, this regeneration was a positive factor in improving function of the hindlimbs during a climbing task, but was not correlated with hindlimb stepping. While the mechanisms of the newly regenerated, functional connections established in a complete spinal adult rat are not yet understood, it is clear that OEG transplantation facilitated axonal regeneration. Now the challenges are to determine how to achieve more robust effects by increasing the number of connections and encourage a functionally beneficial reorganization of the newly established connections between the brain and the spinal cord circuitries.

\section{Supplementary Material}

Refer to Web version on PubMed Central for supplementary material.

\section{Acknowledgments}

This work was supported by the National Institute of Neurological Disorders and Stroke Grant NS054159. We thank Maynor Herrera for providing excellent animal care and surgical support, Sharon Zdunowski for her technical support, Dr. Lance Cai and Andy Fong for their help in developing the robotic system, and Dr. Niranjala Tillakaratne for her constructive guidance and valuable discussions. Also a special thanks to Dr. Cintia MuñozQuiles for her guidance and support with OEG preparations and surgeries.

\section{References}

Cai LL, Fong AJ, Otoshi CK, Liang Y, Burdick JW, Roy RR, Edgerton VR. Implications of assist-asneeded robotic step training after a complete spinal cord injury on intrinsic strategies of motor learning. J. Neurosci. 2006; 26:10564-10568. [PubMed: 17035542]

Boulenguez P, Liabeuf S, Bos R, Bras H, Jean-Xavier C, Brocard C, Stil A, Darbon P, Cattaert D, Delpire E, Marsala M, Vinay L. Down-regulation of the potassium-chloride cotransporter KCC2 contributes to spasticity after spinal cord injury. Nat. Med. 2010; 16:302-307. [PubMed: 20190766]

de Leon RD, Acosta CN. Effect of robotic-assisted treadmill training and chronic quipazine treatment on hindlimb stepping in spinally transected rats. J. Neurotrama. 2006; 23:1147-1163.

de Leon RD, Tamaki H, Hodgson JA, Roy RR, Edgerton VR. Hindlimb locomotor and postural training modulates glycinergic inhibition in the spinal cord of the adult spinal cat. J. Neurophysiol. 1999; 82:359-369. [PubMed: 10400964] 
Edgerton VR, Roy RR. Spasticity: a switch from inhibition to excitation. Nat. Med. 2010; 16:270-271. [PubMed: 20208512]

Frannsen EH, de Bree FM, Verhaagen J. Olfactory ensheathing glia: their contribution to primary olfactory nervous system regeneration and their regenerative potential following transplantation into the injured spinal cord. Brain Res. Rev. 2007; 56:236-258. [PubMed: 17884174]

Fong AJ, Cai LL, Otoshi CK, Reinkensmeyer DJ, Burdick JW, Roy RR, Edgerton VR. Spinal cordtransected mice learn to step in response to quipazine treatment and robotic training. J. Neurosci. 2005; 25:11738-11747. [PubMed: 16354932]

García-Alías G, López-Vales R, Forés J, Navarro X, Verdú E. Acute transplantation of olfactory ensheathing cells or Schwann cells promotes recovery after spinal cord injury in the rat. J. Neurosci. Res. 2004; 75:632-641. [PubMed: 14991839]

Giroux N, Reader TA, Rossignol S. Comparison of the effect of intrathecal administration of clonidine and yohimbine on the locomotion of intact and spinal cats. J. Neurophysiol. 2001; 85:2516-2536. [PubMed: 11387398]

Hochman, S.; Garraway, SM.; Machacek, DW.; Shay, BL. 5-HT receptors and the neuromodulatory control of spinal cord function. In: Cope, TC., editor. Motor Neurobiology of the Spinal Cord. Boca Raton: CRC Press; 2001. p. 47-87.

Keyvan-Fouladi N, Raisman G, Li Y. Functional repair of the corticalspinal tract by delayed transplantation of olfactory ensheathing cells in adult rats. J. Neurosci. 2003; 23:9428-9434. [PubMed: 14561871]

Kubasak MD, Jindrich DL, Zhong H, Takeoka A, McFarland KC, Muñoz-Quiles C, Roy RR, Edgerton VR, Ramón-Cueto A, Phelps PE. OEG implantation and step training enhance hindlimb-stepping ability in adult spinal transected rats. Brain. 2008; 131:264-276. [PubMed: 18056162]

López-Vales R, Forés J, Navarro X, Verdú E. Chronic transplantation of olfactory ensheathing cells promotes partial recovery after complete spinal cord transection in the rat. Glia. 2007; 55:303-311. [PubMed: 17096411]

Lu J, Féron F, Mackay-Sim A, Waite PM. Olfactory ensheathing cells promote locomotor recovery after delayed transplantation into transected spinal cord. Brain. 2002; 125:14-21. [PubMed: 11834589]

Muñoz-Quiles C, Santos-Benito FF, Llamusí MB, Ramón-Cueto A. Chronic spinal injury repair by olfactory bulb ensheathing glia and feasibility for autologous therapy. J. Neuropathol. Exp. Neurol. 2009; 12:1294-1308.

Otoshi, CK. Unpublished doctoral dissertation. Los Angeles, CA: University of California-Los Angeles; 2008. Receptor Plasticity in the Lumbar Spinal Cord: A Move to a Simpler Model.

Polentes J, Stamegna JC, Nieto-Sampedro M, Gauthier P. Phrenic rehabilitation and diaphragm recovery after cervical injury and transplantation of olfactory ensheathing cells. Neurobiol. Dis. 2004; 16:638-653. [PubMed: 15262276]

Ramón-Cueto A, Cordero MI, Santos-Benito FF, Avila J. Functional recovery of paraplegic rats and motor axon regeneration in their spinal cords by olfactory ensheathing glia. Neuron. 2000; 25:425-435. [PubMed: 10719896]

Takeoka A, Jindrich DL, Zhong H, Ziegler MD, Muñoz-Quiles C, Ramón-Cueto A, Roy RR, Edgerton VR, Phelps PE. Evidence for functional reconnectivity of descending motor pathways in adult rats after a complete spinal cord transection and olfactory ensheathing glia transplantation. Soc. Neurosci. Abstr. 2008; 74874.8.

Takeoka A, Kubasak MD, Zhong H, Roy RR, Phelps PE. Serotonergic innervation of the caudal spinal stump in rats after complete spinal transection: effect of olfactory ensheathing glia. J. Comp. Neurol. 2009; 515:664-676. [PubMed: 19496067]

Takeoka A, Kubasak MD, Zhong H, Kaplan J, Roy RR, Phelps PE. Noradrenergic innervation of the rat spinal cord caudal to a complete spinal cord transection: effects of olfactory ensheathing glia. Exp. Neurol. 2010; 222:59-69. [PubMed: 20025875]

Verdú E, García-Alías G, Forés J, López-Vales R, Navarro X. Olfactory ensheathing cells transplanted in lesioned spinal cord prevent loss of spinal cord parenchyma and promote functional recovery. Glia. 2003; 42:275-286. [PubMed: 12673833] 
Ziegler MD, Zhong H, Roy RR, Edgerton VR. Why variability facilitates spinal learning. J. Neurosci. 2010; 30:10720-10726. [PubMed: 20702702] 

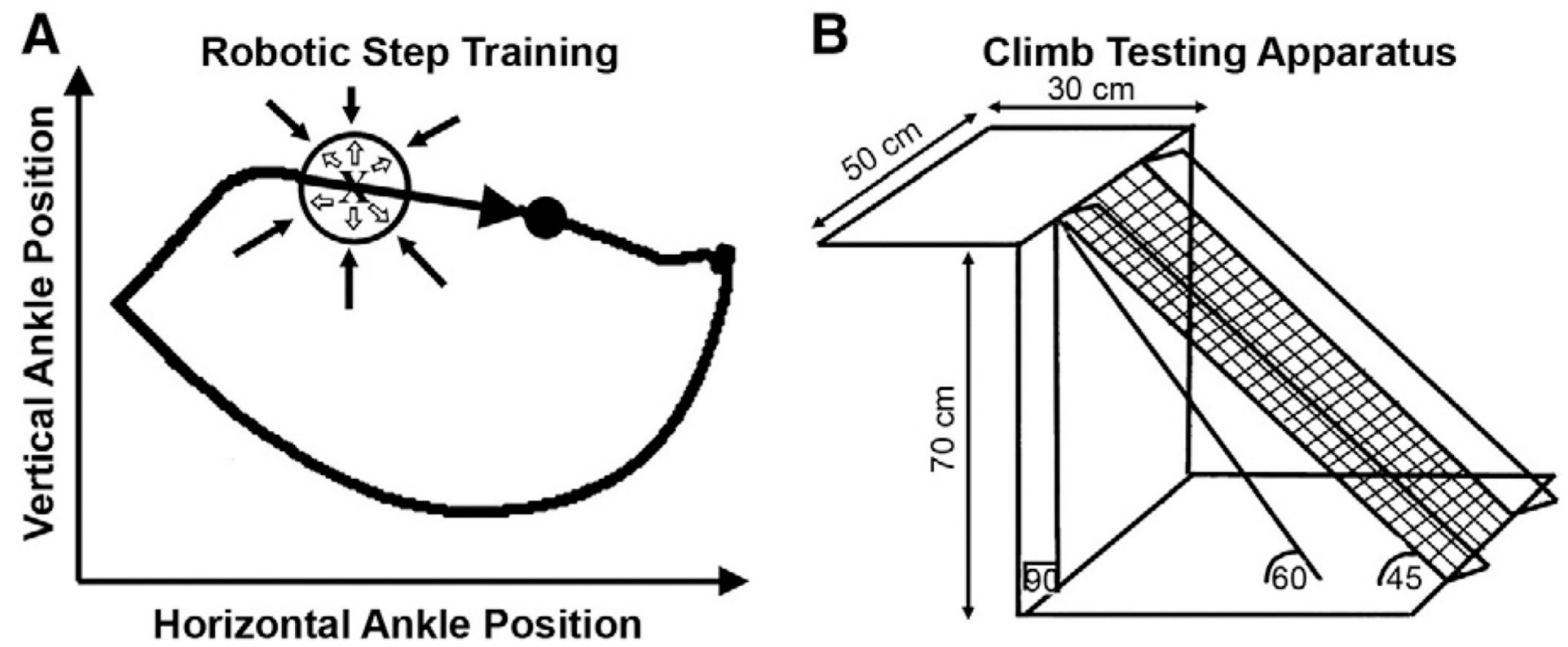

Fig. 1.

Stepping and climbing apparatus. A shows the robotically assisted step training method (Ziegler et al., 2010). If the ankle of the rat is at a position within the open circle (marked by the "X") the robotic arms are passive and the leg is able to move freely in any direction within that area (open arrows). When the ankle leaves the circle the robotic arms guide it back into the open circle. The robotic arms also provide a small force guiding the ankle to the next point (closed circle) in the programmed trajectory. The closed arrows show forces that adjust the ankle position to this area which are proportional to the distance from the desired position. B shows the apparatus used for the climb test (Ramón-Cueto et al., 2000). A platform $(50 \mathrm{~cm} \times 30 \mathrm{~cm})$ with a slippery surface was set up $70 \mathrm{~cm}$ from the floor and a wire grid $\left(2.5 \mathrm{~cm}\right.$ grid holes) was set at three different inclines $\left(45^{\circ}, 60^{\circ}\right.$, and $\left.90^{\circ}\right)$ during testing. 


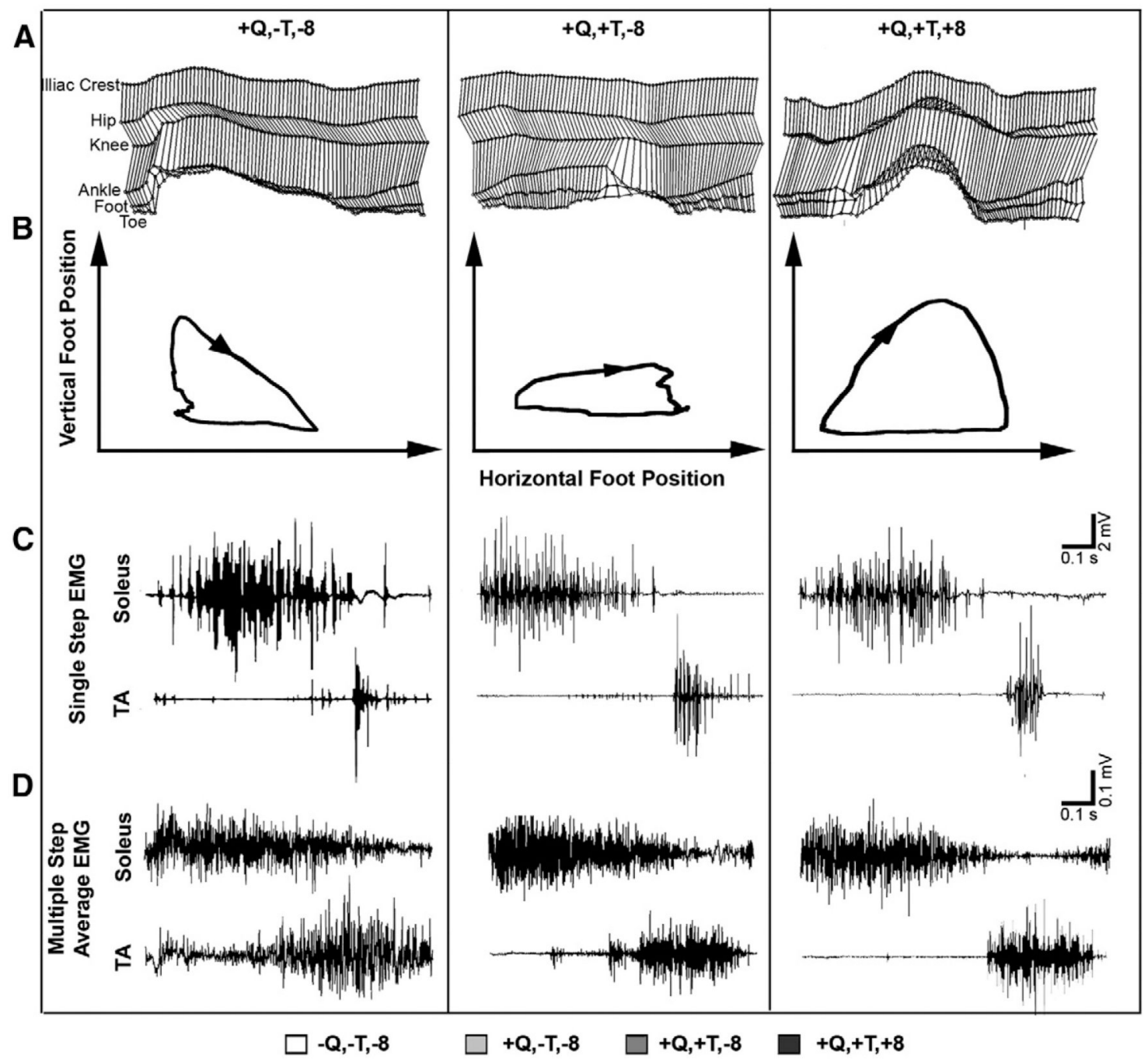

E

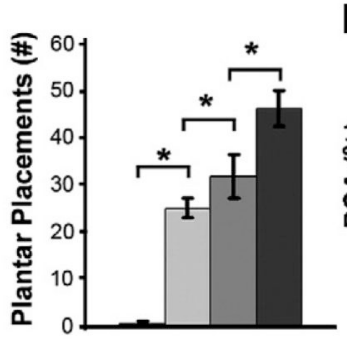

$\mathbf{F}$

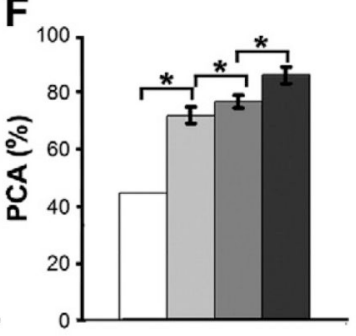

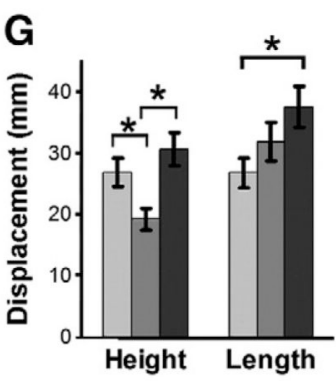

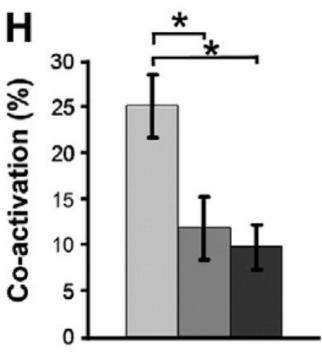

Fig. 2.

Improved stepping through training and 5-HT agonists for Media rats tested $(20 \mathrm{~s})$ after 4 months of training post-transection. Panels A-D show examples of different kinematics aspects of stepping for Media rats under three conditions: after injections of quipazine alone $(+Q)$, left column; after step training (+T) plus injection of quipazine, center column; and after step training plus quipazine plus 8-OH-DPAT (+8), right column. A shows a stick figure diagram of a representative step under each condition, from markers at the iliac crest, hip, knee, ankle, foot, and toe. The two examples from the trained groups are from the same trained rat. B shows the average step trajectory, taken from all completed steps in one session, for the rats shown in A. C shows the EMG activity in the soleus and TA muscles 
from a single plantar step and D shows the average EMG of 10 steps from the rats shown in A-C. E shows the average number of plantar placements taken during $20 \mathrm{~s}$ of stepping by each of the same three groups as above plus a Media group receiving no interventions. F shows the average PCA analysis (see Methods) for the same groups as in E. G shows the mean height and length of the step trajectory. H shows the average percent time coactivation of the soleus and TA muscles. Bars in E-H are mean \pm SEM for 10 rats/group, except $+\mathrm{Q},+\mathrm{T}$, and +8 which is a group of 7 rats. ${ }^{*}$, significant difference between groups at $p<0.05$. 
A
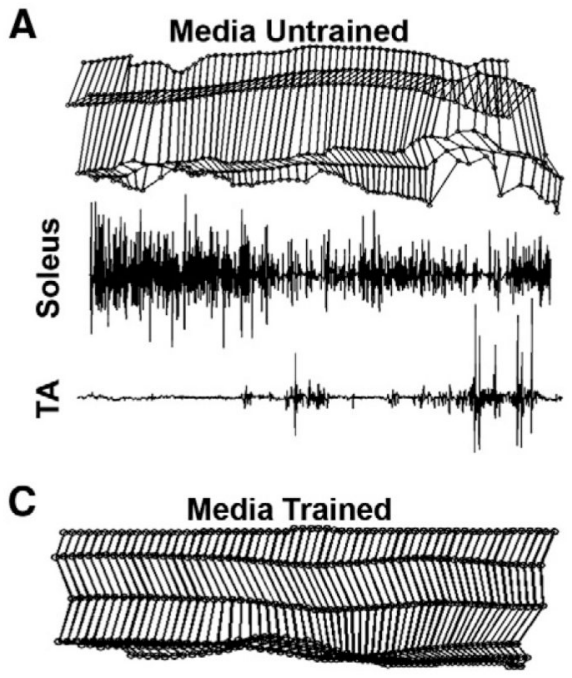

N/A

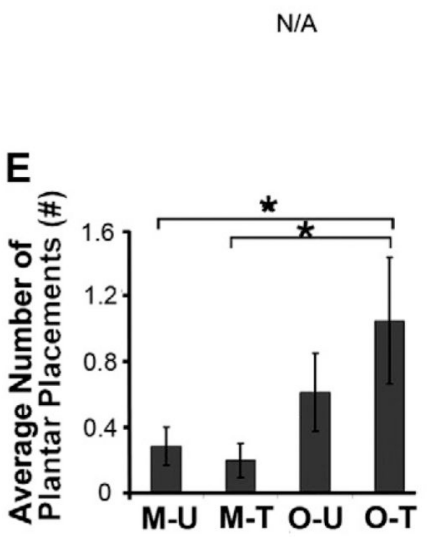

$\mathbf{F}$

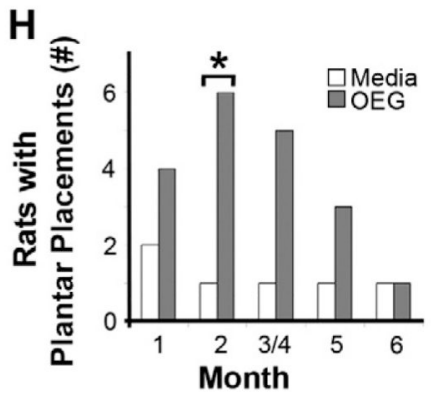

Fig. 3.
B

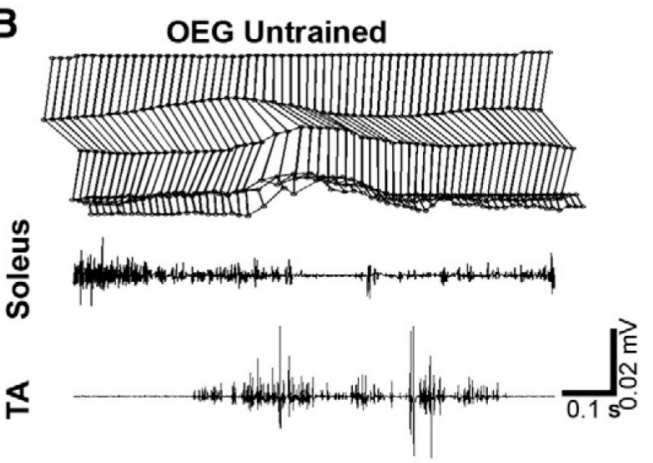

D

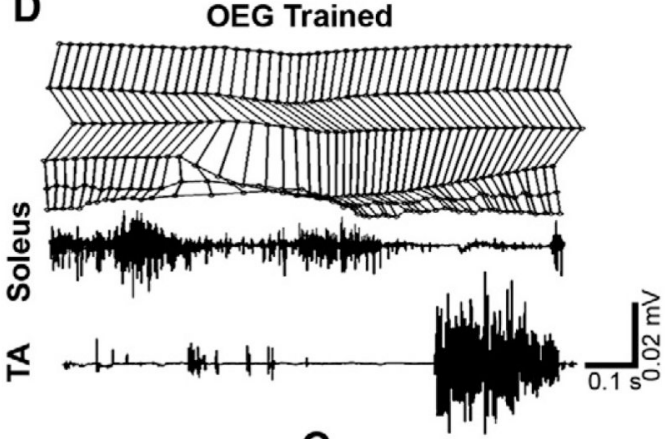

G
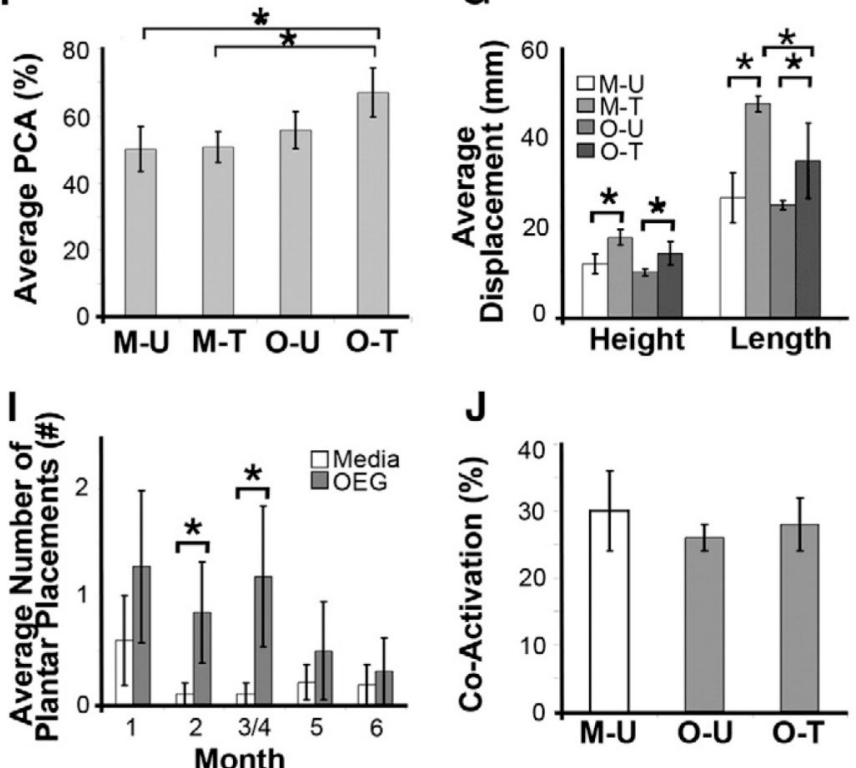

J

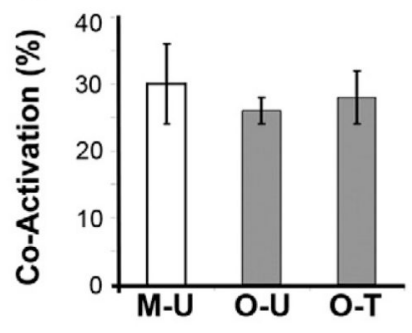

Step kinematics of Media and OEG rats taken 6 months post-transection, unless otherwise noted. A-D show a stick figure diagram of a typical step from a representative rat from each group. Underneath each stick figure is the averaged raw EMG activity of the soleus and TA during stepping for each rat for one testing session, except for the Media trained as no rat from this group stepped in months four through six (N/A). E shows the average number of plantar placements taken by the Media untrained (M-U), Media trained (M-T), OEG untrained $(\mathrm{O}-\mathrm{U})$, and $\mathrm{OEG}$ trained $(\mathrm{O}-\mathrm{T})$ groups over the 6-month experimental period. $\mathrm{F}$ shows the average PCA analysis for each group of rats over all testing sessions. G shows the average height and length for all plantar placements taken by each group over all testing 
sessions. $\mathrm{H}$ shows the total number of OEG and Media rats that took plantar placement steps each month. I shows the average number of plantar placements taken by OEG and Media rats during each month. $\mathrm{J}$ shows the percent time of co-activation of the soleus and TA for the averaged step EMG data shown in A, B, and D. Bars in E-G and $\mathrm{J}$ are mean \pm SEM for 10 rats/group. Bars in I are \pm SEM for 15-20 rats/group. *, significant difference between groups at $p<0.05$. 

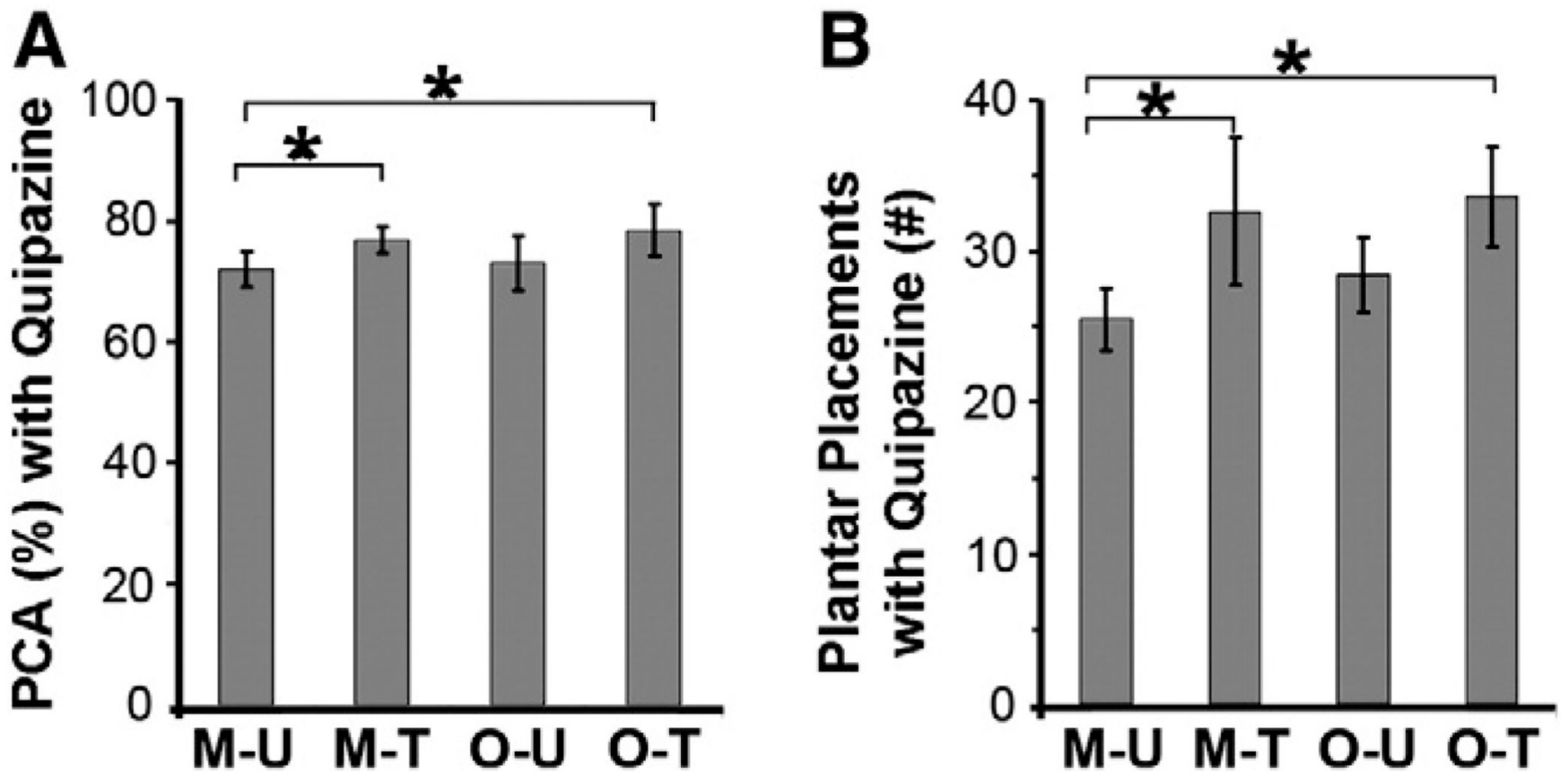

Fig. 4.

Stepping ability of Media and OEG rats with quipazine administration. A shows the PCA analysis and B the number of plantar placement steps for each group for $20 \mathrm{~s}$ of stepping after quipazine administration. Bars are mean \pm SEM for 10 rats/group. Group abbreviations, same as in Fig. 3. *, significant difference between groups at $p<0.05$. 

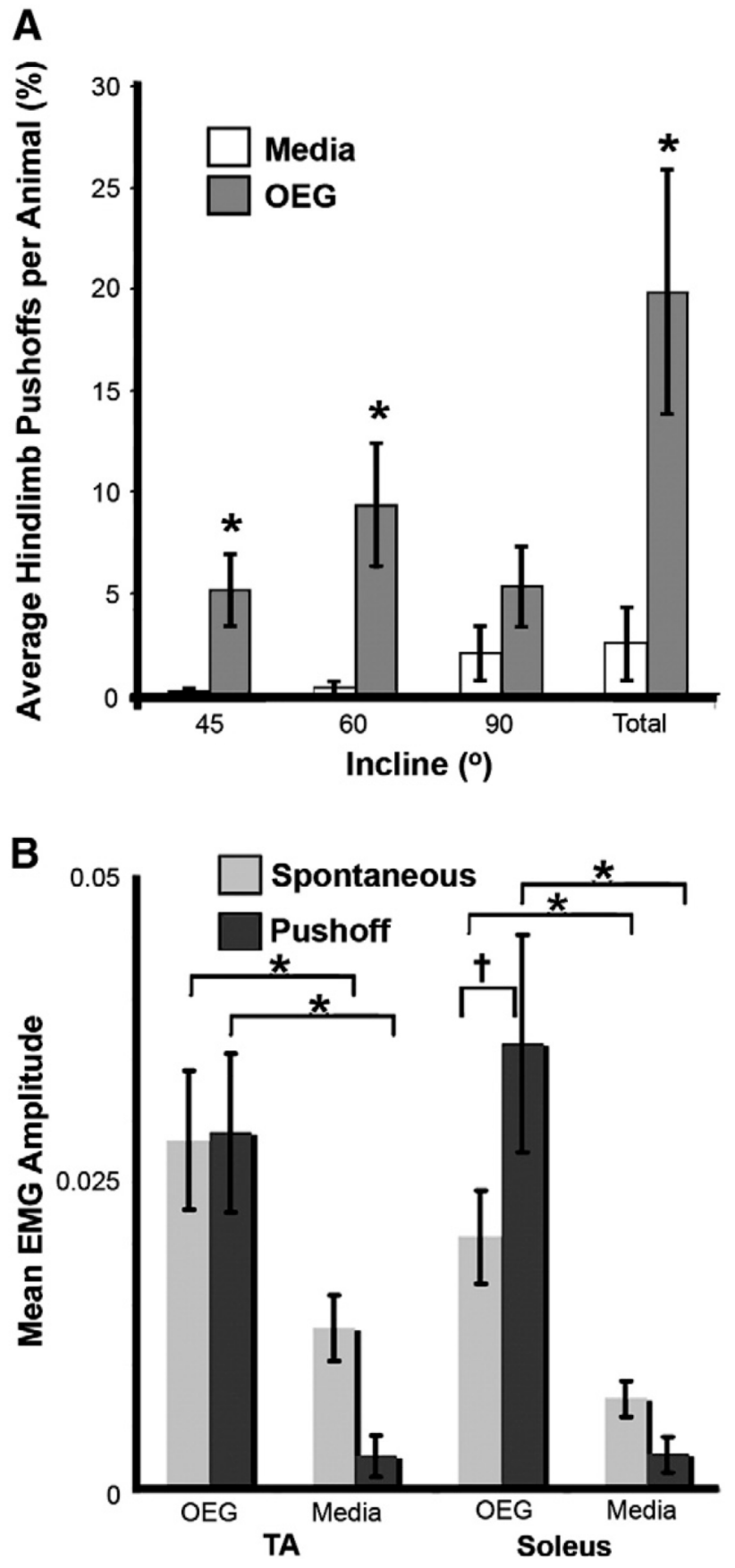

Fig. 5.

Hindlimb usage during climbing for Media untrained and OEG untrained rats A shows the average number of times that each of the OEG or Media rats pushed off with their hindlimbs during the climbing task. B shows the mean $( \pm$ SEM) EMG amplitude of the TA and soleus muscles in the OEG and Media groups for the pushoff and at all other times (spontaneous) during the climbing task. All tests were done on 6 rats per group. *, significant difference between OEG and Media groups at $p<0.05 . \dagger$, significant difference within the OEG group at $p<0.05$. 

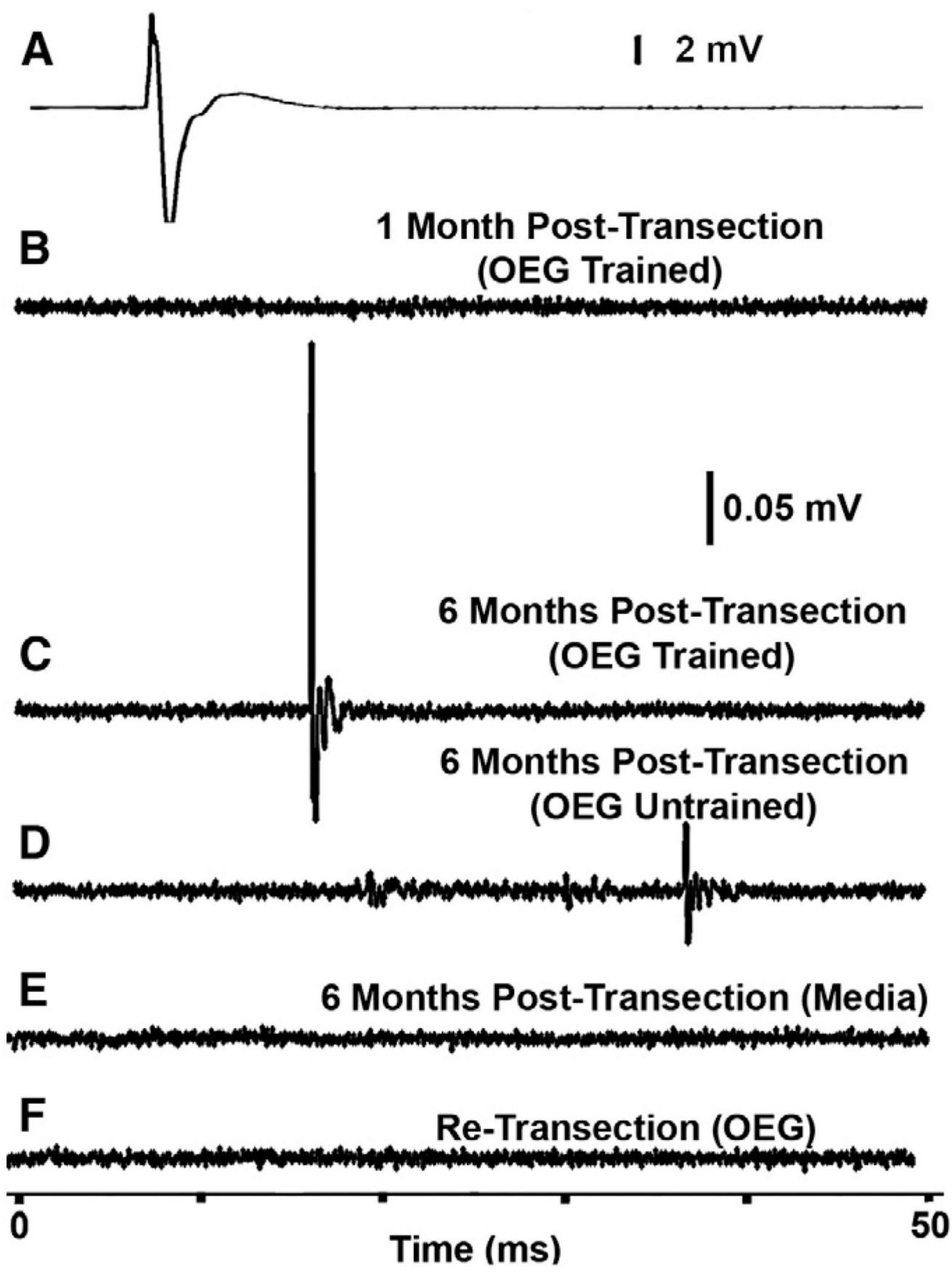

Fig. 6.

Examples of MEP at different time points during the experiment. A shows a MEP response to brainstem stimulation for an intact rat. The recording saturated at $10 \mathrm{mV}$. Therefore a flat portion of the signal appears if the values are higher than $10 \mathrm{mV}$. B is a MEP response for an OEG trained rat 1 month post-transection. $\mathrm{C}$ is the recovered MEP in the OEG rat in $\mathrm{B} 6$ months post-transection. $\mathrm{D}$ is a MEP response 6 months post-transection in an OEG untrained rat. E shows the lack of any MEP response 6 months post-transection in a Media rat. $\mathrm{F}$ shows the lack on a MEP response from the same rat in graphs $\mathrm{B}$ and $\mathrm{C}$ after retransection of the spinal cord at a level rostral to the initial transection. The scale bar in $\mathrm{C}$ is the same for B-F. 
A

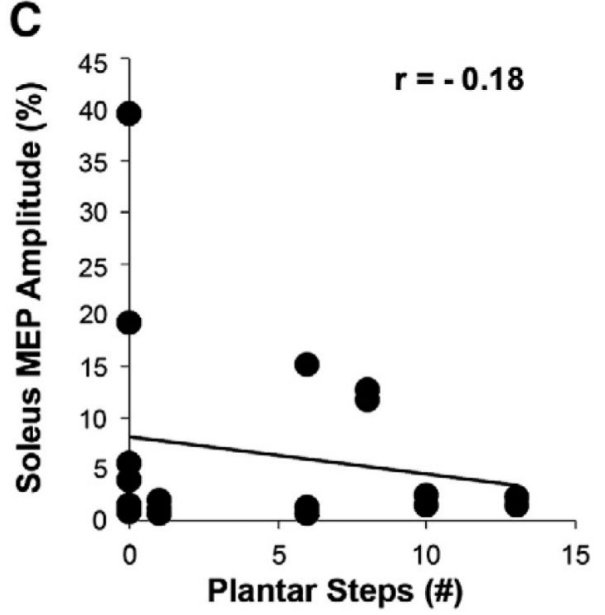

E

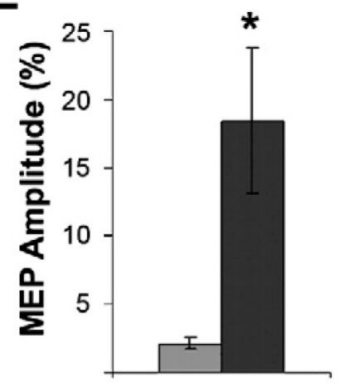

F
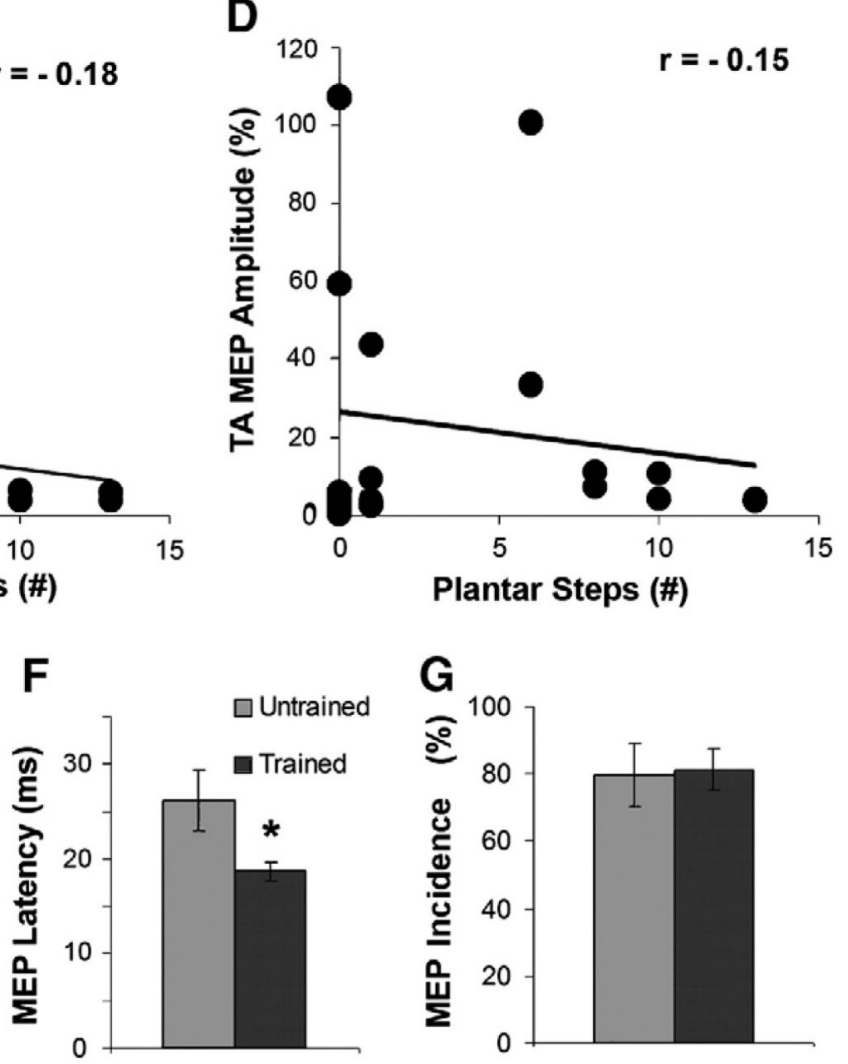

Hindlimb Pushoffs

During Climbing (\#)

B

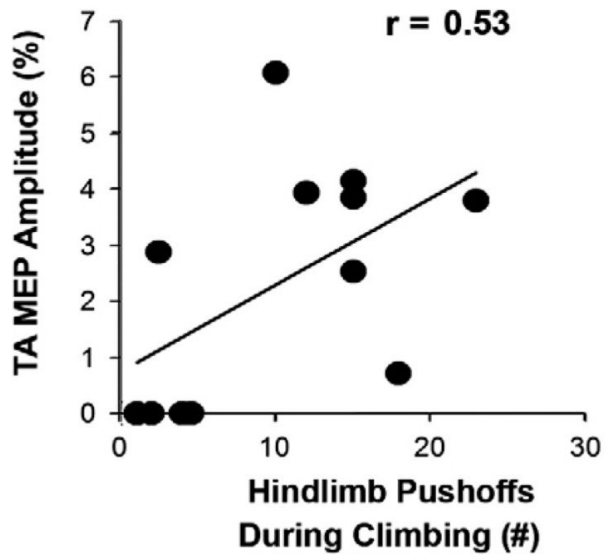

D

G

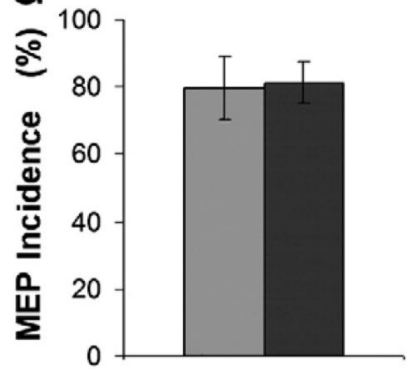

Fig. 7.

MEP amplitudes relative to hindlimb performance in trained and untrained OEG rats 6 months post-transection. A and B show the relationship between the number of times the hindlimbs were used (pushing off) and the normalized MEP amplitude ((MEP Amplitude $(\mathrm{mV}) / \mathrm{Max}$ Stepping EMG $(\mathrm{mV})) \times 100))$ in the soleus and TA muscles of untrained OEG rats, respectively. Each dot represents the number of pushoffs for a single leg ( 2 dots per rat). $\mathrm{C}$ and $\mathrm{D}$ show the relationship between the number of plantar placement steps taken by each trained and untrained OEG rat and the normalized MEP amplitude of the soleus and TA muscles, respectively. E-G show the differences in the normalized amplitude $(\mathrm{E})$, latency $(F)$, and incidence $(G)$ of the MEP response between OEG trained and untrained 
rats. The correlation plots are based on data from 6 OEG untrained rats (A and B) or 8 OEG trained and 5 OEG untrained rats $(\mathrm{C}-\mathrm{D})$. Bar graphs in $(\mathrm{E}-\mathrm{G})$ are means \pm SEM for 8 OEG trained and 5 OEG untrained rats.*, significant difference between groups at $p<0.05$. 

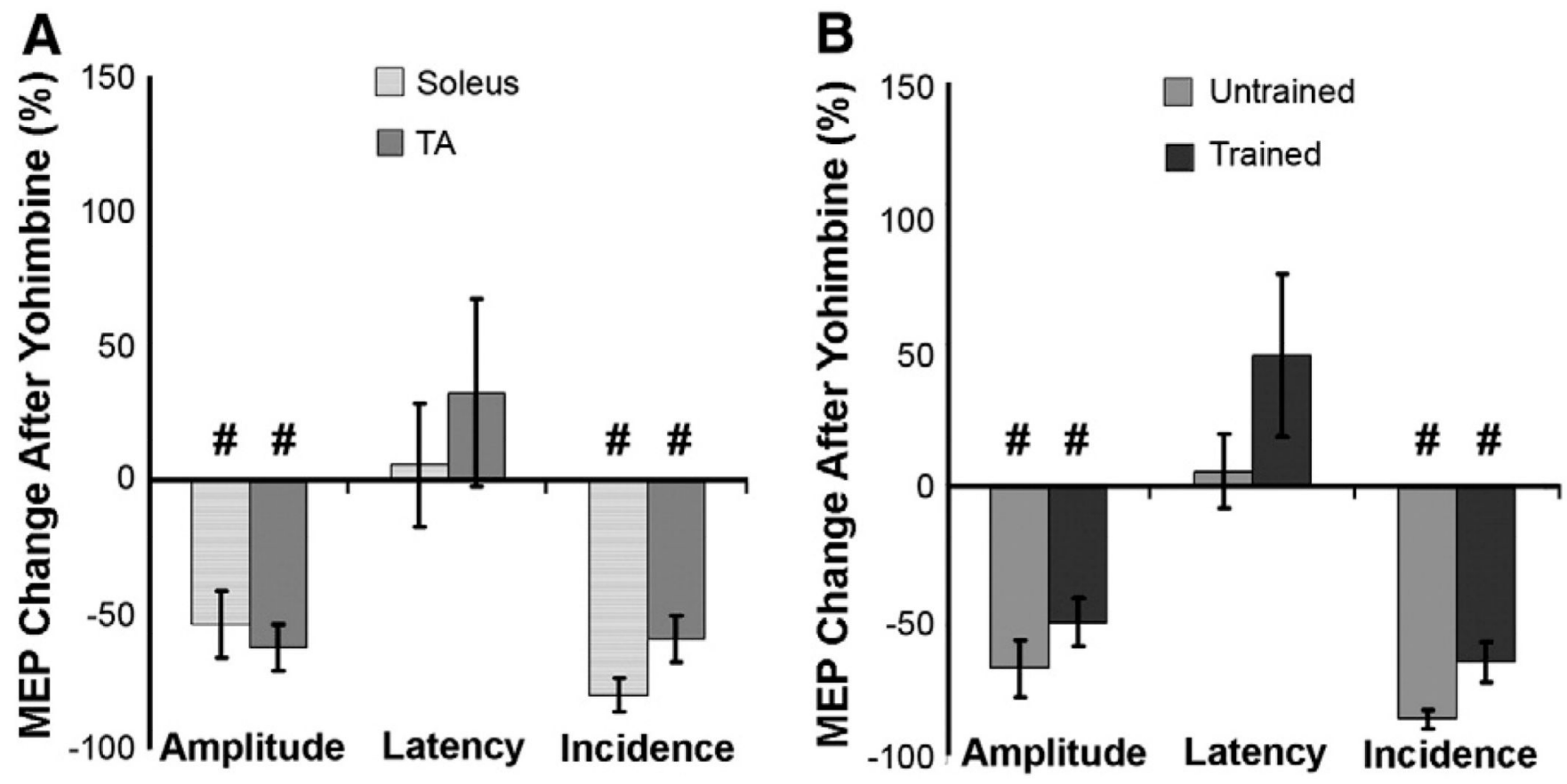

Fig. 8.

MEP modulation due to yohimbine, a $\mathrm{NA}_{2}$ receptor antagonist. $\mathrm{A}$ and $\mathrm{B}$ show the MEP response of all OEG rats after intrathecal injection of yohimbine. A shows the percent change in MEP amplitude, latency, and incidence for each muscle post- compared to preinjection. B shows the percent change in MEP amplitude, latency, and incidence postcompared to pre-injection in both muscles of OEG trained and untrained rats. Bars are mean \pm SEM for 7 rats. \#, significant difference between pre- and post-yohimbine injection at $p<0.05$. 

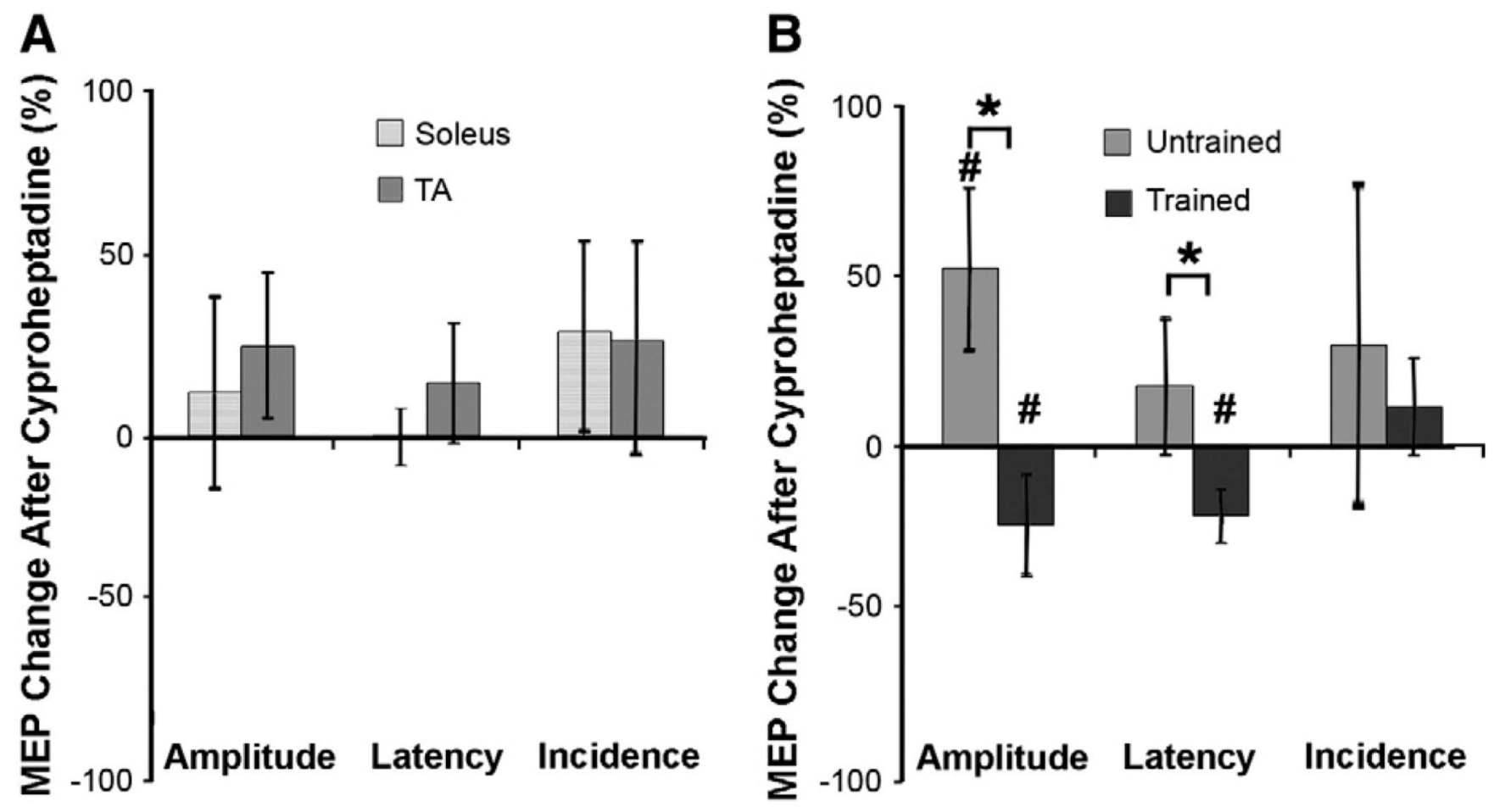

Fig. 9.

MEP modulation due to cyproheptadine, a 5- $\mathrm{HT}_{2}$ receptor antagonist. A and $\mathrm{B}$ show the MEP response of all OEG rats after intrathecal injection of cyproheptadine. A shows the percent change in MEP amplitude, latency, and incidence for each muscle post- compared to pre-injection. B shows the percent change in MEP amplitude, latency, and incidence postcompared to pre-injection in both muscles of OEG trained and untrained rats. Bars are mean \pm SEM for 5 rats. *, and \# significant difference between groups and between pre-and postcyproheptadine injection, respectively, at $p<0.05$. 

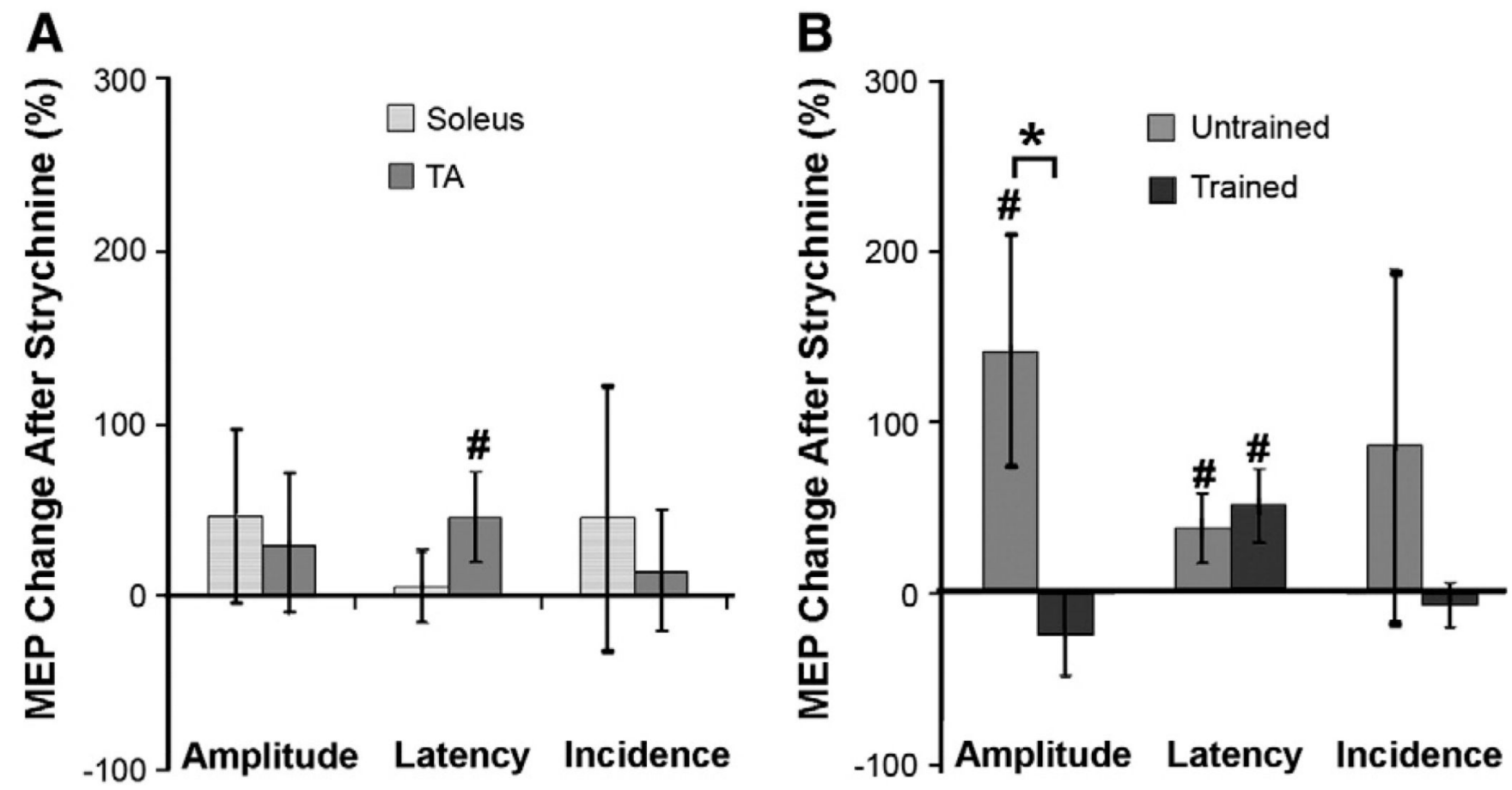

Fig. 10.

MEP modulation due to strychnine, a glycinergic receptor antagonist. A and B show the MEP response of all OEG rats after intrathecal injection of strychnine. A shows the percent change in MEP amplitude, latency, and incidence for each muscle post- compared to preinjection. B shows the percent change in MEP amplitude, latency, and incidence postcompared to pre-injection in both muscles of OEG trained and untrained rats. Bars are mean \pm SEM for 7 rats. *, and \#, significant difference between groups and between pre-and poststrychnine injection, respectively, at $p<0.05$. 


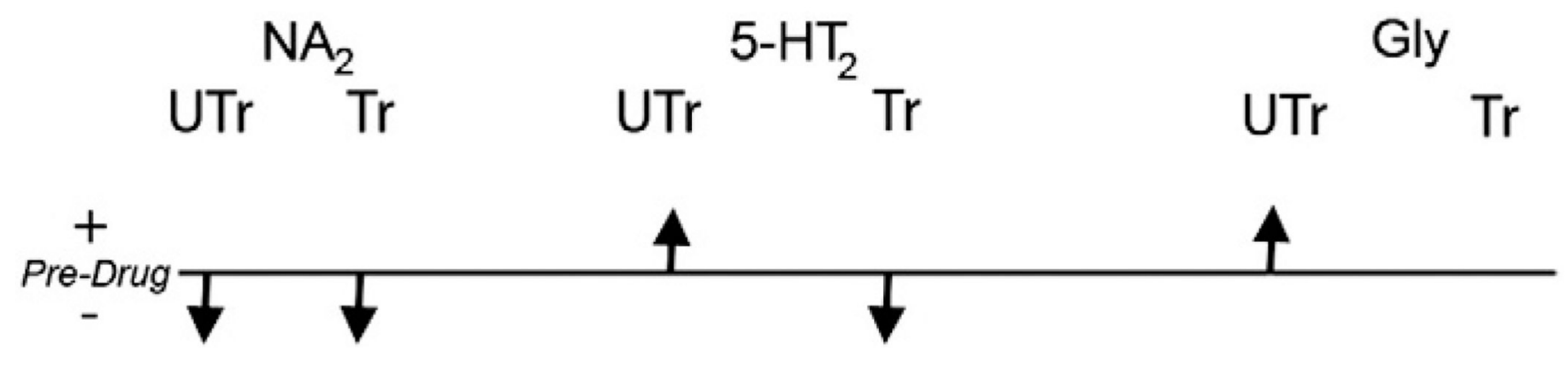

Fig. 11.

Graphic summary of the effects of each receptor antagonist on the amplitude of the MEP response in untrained (UTr) and trained (Tr) OEG rats as shown in Figs. 8-10. 


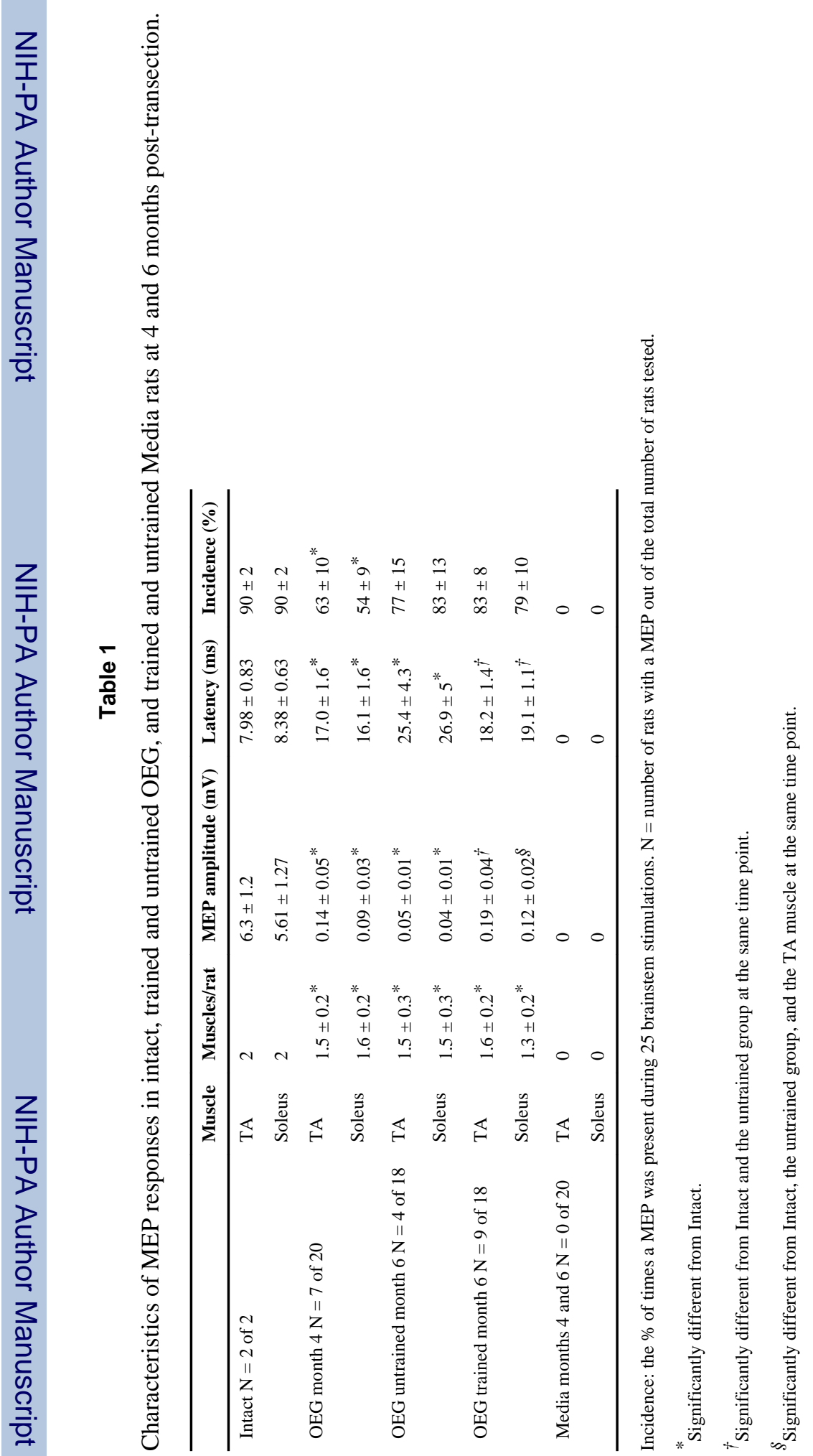

Exp Neurol. Author manuscript; available in PMC 2011 May 3. 